\title{
The Diabetes-Prone NZO/HI Strain. II. Pancreatic Immunopathology
}

\author{
Erika Junger, Lieselotte Herberg, Kay Jeruschke, and Edward H. Leiter \\ Diabetes Research Institute (EJ, LH, KJ), Auf'm Hennekamp, Düsseldorf, Germany; and The Jackson Laboratory \\ (EHL), Bar Harbor, Maine
}

\begin{abstract}
SUMMARY: We report the first combined light and electron microscopic analysis of the pancreas during the development of type 2 diabetes in the New Zealand Obese (NZO) mouse. As in most other polygenic rodent models of type 2 diabetes, hyperglycemia associated with beta cell destruction is male sex-limited. Increasing degrees of hyperinsulinemia and transition to diabetes were clearly reflected by the islet volume fraction, by the beta cell granulation state, and by ultrastructural changes, primarily of the endoplasmic reticulum. One of the unusual histopathologic features of NZO mice of both sexes was the presence of B-lymphocyte enriched leukocytic aggregates in the pancreas. Immunocytochemical analysis of the pancreas of 52-week-old diabetic males indicated enrichment for CD19 ${ }^{+}$B lymphocytes. Staining of adjacent sections for CD3 and CD5 indicated CD5 coexpression on some of the CD19 ${ }^{+}$cells, suggesting the presence of the B1-B subset associated with generation of natural autoantibodies in other autoimmune-prone New Zealand mouse strains. In addition, plasma cells in peri-insular leukocytic infiltrates were identified by electron microscopy. Hence, although autoimmunity has previously proven to be a secondary manifestation of beta cell destruction in most rodent models of type 2 diabetes, the present observations suggest that $B$ lymphocyte function, in association with male gender, may contribute to the development of insulin resistance and chronic hyperglycemia in the NZO model. (Lab Invest 2002, 82:843-853).
\end{abstract}

$N$ ew Zealand Obese (NZO)/HI mice of both sexes develop juvenile-onset obesity that is polygenic in origin (Taylor et al, 2001). A progressively more severe insulin resistance leads to impaired glucose tolerance and precipitates chronic type 2 diabetes (T2D) in approximately $50 \%$ of males in this substrain (Leiter et al, 1998). In the companion report, we show that the $\mathrm{NZO} / \mathrm{HI}$ strain shares the systemic lupus erythematosus-associated $H 2^{z}$ haplotype with the related New Zealand White (NZW)/LacJ strain, and also resembles another related (and autoimmunity-prone) strain, New Zealand Brown (NZB)/BINJ, in terms of certain hematologic anomalies (Haskell et al, 2002) as well as in producing autoantibodies to single- and double-stranded DNA (Melez et al, 1980, 1985). NZB mice develop pancreatic perivascular/periductular leukocytic infiltrates adjacent to the islets ("periinsulitis"), but mice of this strain do not develop overt diabetes (Seemayer and Colle, 1984). However, as shown in the companion report, outcross of NZO/HILt and NZB/BINJ progenitors produced F1 males exhib-

\section{DOI: 10.1097/01.LAB.0000018917.69993.BA}

Received January 14, 2002.

This study was supported by the Ministerium für Wissenschaft und Forschung des Landes Nordrhein Westfalen (Düsseldorf) and by the Bundesministerium für Gesundheit (Berlin). The Bar Harbor colony was supported by grants from NIH-NCRR-88911 and DK-56853. Institutional shared services of The Jackson Laboratory were supported by National Cancer Institute Cancer Center Support Grant CA-34196 to The Jackson Laboratory.

Address reprint requests to: Dr. Edward H. Leiter, The Jackson Laboratory, 600 Main Street, Bar Harbor, Maine 04609. E-mail: ehl@jax.org iting an accelerated rate of both obesity and obesityinduced diabetes ("diabesity") in 100\% of these hybrid males. We have recently used a new flow cytometric assay to confirm an earlier report (Harrison and Itin, 1979) that NZO mice develop autoantibodies to the insulin receptor. We further found that spleens of 4-month-old NZO males contained even higher numbers of B1-B lymphocytes than either NZB or NZW. This is the postpubertal time period in which insulin receptor autoantibodies in serum are detected and gradual loss of glycemic control emerges in NZO/HI males. The function of B1-B cells in vivo is thought to be for production of natural antibodies that comprise the "natural memory" immune system's defense before adaptive immunity is established (Martin and Kearney, 2001). Natural antibodies that are present in a lymphoproliferative environment exhibited by NZ strains are thought to cause expansion of autoantibody-producing cells. Given this association between the B1-B lymphocyte subpopulation and autoantibody production, we introduced into the NZO background a targeted mutation in the immunoglobulin heavy chain (Igh- $\left.6^{\operatorname{tm} 1 \mathrm{Cgn}}\right)$ (Taguchi et al, 2001) and prevented B lymphocyte development. In these Blymphocyte-deficient mice, development of diabetes, but not obesity, was suppressed. Because NZO/HI males not only develop clinical T2D at a reasonably high frequency, but also can be maintained without insulin treatment in a chronically diabetic condition for up to a year of age, we had the opportunity to compare the histopathology and immunopathology of the pancreas in both normoglycemic-hyperinsulinemic and chronically diabetic males versus nondiabetic 
females. Here, we report several unusual immunopathologic features of the peri-insular infiltrates in aging mice of this strain; namely, the presence of a population of $\mathrm{CD}_{19}{ }^{+}$and $\mathrm{CD}^{+} \mathrm{B}$ lymphocytes, and the ultrastructural identification of plasma cells.

\section{Results}

\section{Metabolic Phenotypes in NZO/HI Mice}

Establishment of chronic hyperglycemia in NZO/HI and NZO/HILt mice is male sex-limited as is found in numerous other rodent models of T2D (Leiter and Herberg, 1997). Figure 1 provides individual blood glucose (BG) and serum immunoreactive insulin (IRI) values of the 52-week-old NZO/HI collective from the Düsseldorf colony. In females, normal BG concentrations were observed over the lifetime up to the time of necropsy at 52 weeks (Fig. 1A). Likewise, serum IRI in the fed state clustered tightly within the normal range, with only one female exhibiting a moderate elevation. In contrast, approximately half of the males developed nonfasting hyperinsulinemia (IRI $>50 \mu \mathrm{U} / \mathrm{ml})$ by the 36-week age-point and approximately $50 \%$ exhibited nonfasting hyperglycemia (BG $>250 \mathrm{mg} / \mathrm{dl}$ ) at this time point (Fig. 1B). As shown in Figure 1, males with the most severe hyperglycemia generally exhibited the lowest plasma insulin levels. The individual males depicted in Figure 1B by closed symbols represent the group of 20 males selected for analysis of pancreatic histopathology at 52 weeks. They included 1 normoinsulinemic and normoglycemic male, 7 hyperinsulinemic and normoglycemic males, and 12 diabetic males. Figure $1 \mathrm{C}$ shows the correlation between serum |R| and BG for this subset; males with the most severe hyperglycemia ( $>400 \mathrm{mg} / \mathrm{dl}$ at 52 weeks) exhibited serum IRI concentrations in the normal or subnormal range $(<50 \mu \mathrm{U} / \mathrm{ml})$. This clinical heterogeneity in metabolic phenotypes of aging $\mathrm{NZO} / \mathrm{HI}$ males has been reported previously and represents a threshold phenomenon (Leiter et al, 1998; Reifsnyder et al, 2000).

\section{Female Gender Promotes Beta Cell Survival}

Figure 2 contrasts the radically different appearance of islets in normoglycemic females (Fig. 2A) versus hyperinsulinemic but normoglycemic males (Fig. 2B) and atrophic islets in a male shortly after diabetes onset (Fig. 2C). The histopathology of the pancreatic islets reflected the female gender-biased resistance to development of hyperinsulinemia and hyperglycemia. Increases in islet size (a combination of beta cell hypertrophy and hyperplasia) were noted in pancreata of many females sampled at 24 weeks of age. Regardless of whether a normal or enlarged spectrum of islet sizes was observed, islets in female pancreata at any age sampled remained strongly aldehyde fuchsinpositive, correlating with the absence of marked hyperinsulinemia (Fig. 2A). During prodromal and early diabetes stages in males (eg, up to 24 weeks of age), pancreatic islets underwent both hypertrophy and hyperplasia of beta cell mass. At this time, aldehyde fuchsin stainability of beta cells (representative of beta
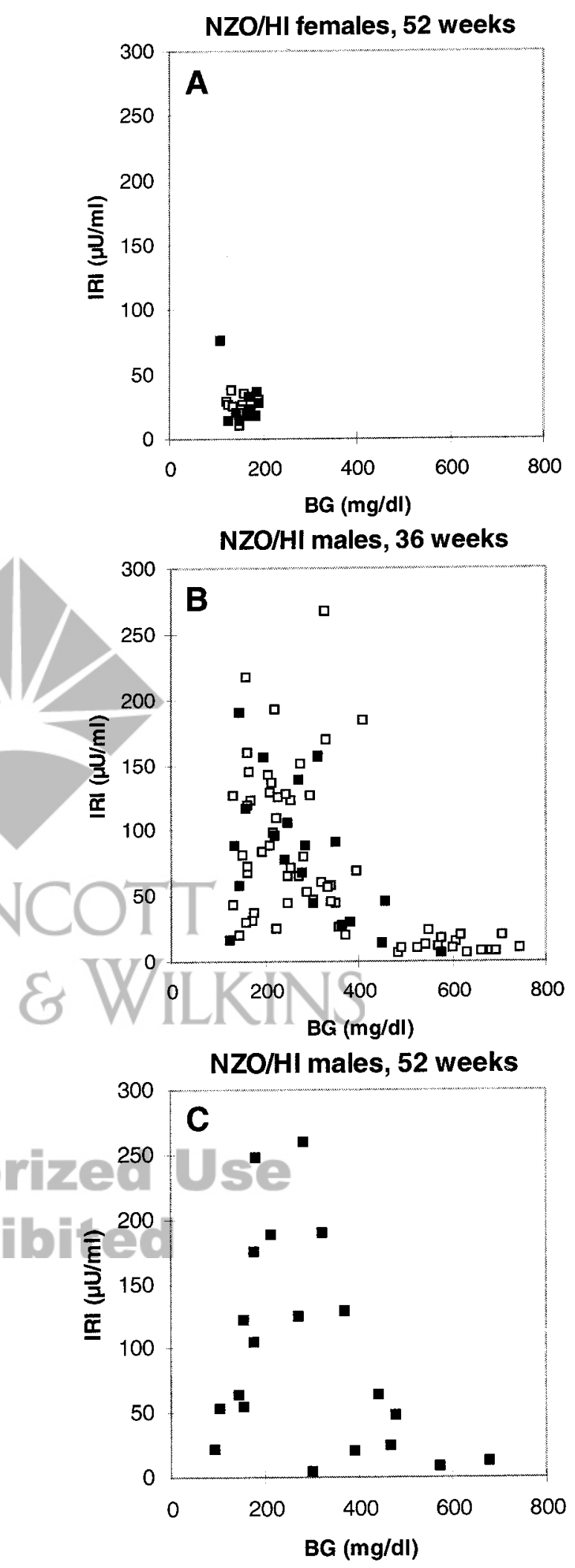

Figure 1.

Scattergram of serum insulin (IRI) and blood glucose (BG) values in aging NZO/HI mice. A, 52-week-old females. B, 36-week-old males. Within this group, 20 males were selected for further aging (closed symbols). C, The same 20 males at the age of 52 weeks. All individuals denoted by closed symbols represent mice from which pancreata were sampled for morphologic analysis at the age of 52 weeks. 

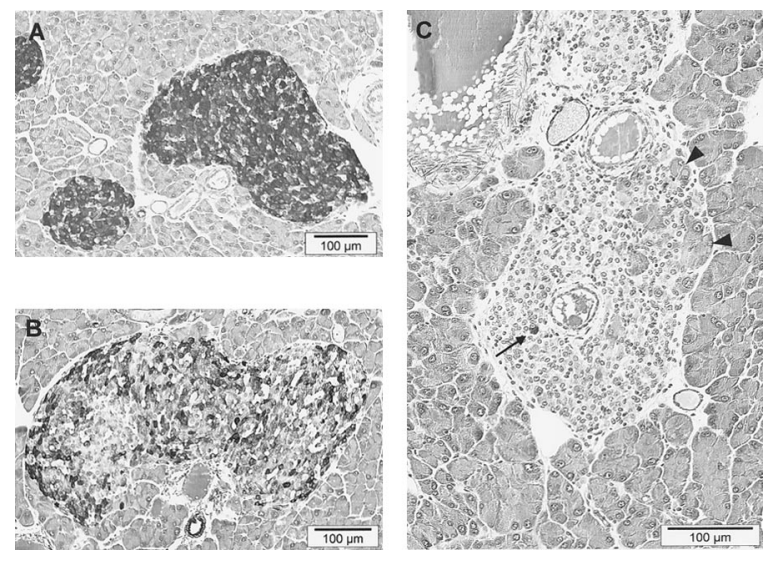

Figure 2.

Aldehyde fuchsin stained pancreas sections of NZO/HILt mice. Representative islet profiles are shown. A, Well-granulated islets of a female at the age of 29 weeks. B, Partially degranulated and hyperplastic islet of a hyperinsulinemic male at the age of 32 weeks. C, Atrophic islet of a 13.5-week-old diabetic male. Islet cells are aldehyde fuchsin-negative except for one granulated cell (arrow). Arrowheads indicate inclusions of exocrine cells. Leukocytes are seen to disseminate into the adjacent exocrine tissue.

cell granulation state) varied considerably, with some pancreata showing partial beta-degranulation (Fig. $2 \mathrm{~B})$, whereas others showed the heavy granulation levels characteristic of beta cells in female islets. In males, this phase was associated with development of hyperinsulinemia. However, usually between 24 and 52 weeks of age, islet atrophy, associated primarily with loss of beta cells (Fig. 2C), became the prevalent phenotype in chronically diabetic males. In the islet depicted, almost all islet beta cells were aldehyde fuchsin-negative, indicating an absence of insulin storage in residual beta cells. Atrophic changes included reduction in beta cell mass frequently accompanied by fibrotic changes around the islet perimeters. Islets in chronically diabetic males became irregular in structure due to inclusion of exocrine cells ("exocrinization") and intra-islet ducts. Fatty infiltration of the pancreas was also commonly observed.

Figure 3 contrasts the difference in ultrastructural

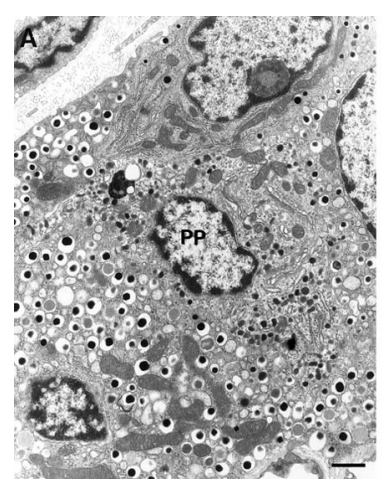

Figure 3.

Electron micrographs of islet sections. A, Detail of an islet of a 52-week-old female. Fully granulated beta cells surround one pancreatic polypeptide cell (PP). B, Detail of an islet of an age-matched chronically diabetic male. Most beta cells are degranulated. Two PP cells (arrowheads) are depicted adjacent to one residual granulated beta cell. ( $\mathrm{Bar}=1 \mu \mathrm{m}$.) appearance of well-granulated beta cells in an islet of a 52-week-old nondiabetic female (Fig. 3A) versus the extensively degranulated appearance of an islet from an age-matched and chronically diabetic male. The marked reduction in insulin storage granules was generally associated with a dilatation of the rough endoplasmic reticulum (Fig. 3B). Beta cells containing mitochondria with a less dense matrix and partly damaged cristae were also observed (not shown). These ultrastructural features are consistent with extreme secretory stress placed on residual beta cells.

Data in Figure 4 demonstrate that the islet volume fraction, $V_{v}$ isl, is closely related to the metabolic state of the individual animal. The correlation between $V_{v}$ isl and BG concentrations (Fig. 4A) measured at the time of necropsy at 52 weeks (Fig. 1C) accentuates the difference between females and males. Figure $4 \mathrm{~A}$ shows that a higher volume fraction of islets is required in males than in females to avoid hyperglycemia. Complementary to this finding, the data in Figure $4 \mathrm{~B}$ show the correlation between $\mathrm{V}_{\mathrm{v}}$ isl and IRI concen-

\section{Correlation between Vvisl and BG at 52 weeks}

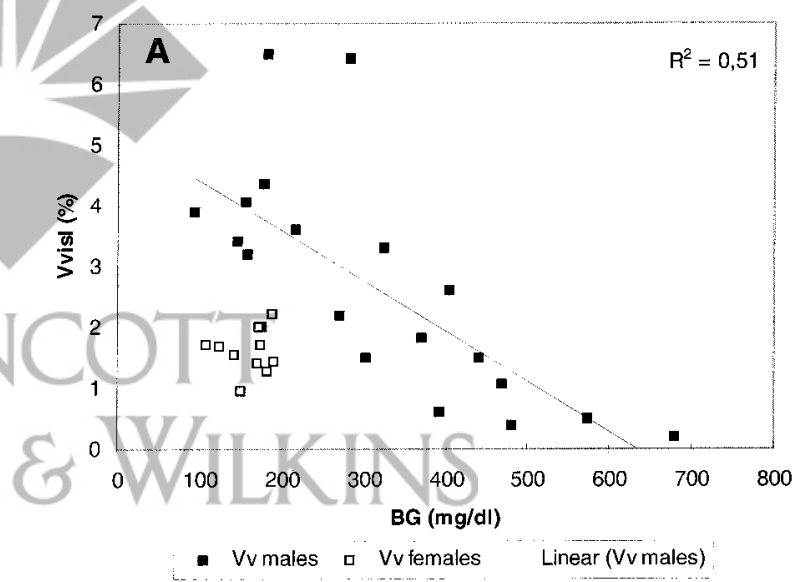

Correlation between VvisI and IRI at 52 weeks

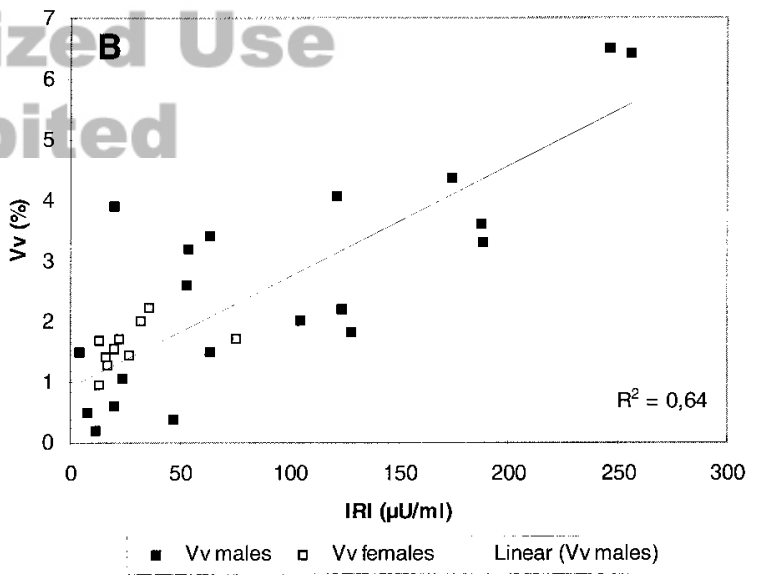

Figure 4.

Correlations between fractional islet volumes, $\mathrm{V}_{\mathrm{v}}$ isl, and metabolic parameters. $\mathrm{V}_{\mathrm{v}}$ isl were determined by point counting morphometrics on sections from 52-week-old-females (open symbols) and age-matched males (closed symbols). A, V Visl were correlated with BG concentrations measured at the time of necropsy. $B, V_{v}$ is were correlated with serum IRI values measured at the time of necropsy. 
trations, the latter also being measured at the time of necropsy (Fig. 1C). The data demonstrate that increases in IRI concentrations are reflected by approximately proportional increases of $\mathrm{V}_{\mathrm{v}}$ isl. It was found $\mathrm{V}_{\mathrm{v}}$ isl varied within more than one order of magnitude, ranging from $<0.5 \%$ for severely diabetic animals to $>5 \%$ for the most hyperinsulinemic animals. The upper range of $\mathrm{V}_{\mathrm{v}}$ isl is comparable with values given for extremely insulin resistant mice doubly heterozygous for targeted mutations in the insulin receptor and the insulin receptor substrate-1 (Kido et al, 2000). The number of islets of all size classes was found to increase with increasing $\mathrm{V}_{\mathrm{v}}$ isl and consequently, with IRI levels. On average, 60 islet profiles per $\mathrm{cm}^{2}$ tissue were recorded in pancreas sections of females. Islet densities up to 100 islet profiles per $\mathrm{cm}^{2}$ were observed in normoglycemic and hyperinsulinemic males. However, the largest increments in $\mathrm{V}_{\mathrm{v}}$ isl were found to be due to a small fraction ( 2 to 20 islet profiles per $\mathrm{cm}^{2}$ tissue) of extremely hyperplastic islets with profile diameters between 0.5 and $1 \mathrm{~mm}$ predominantly clus- tering along the main ducts. These enlarged islets were most prevalent in hyperinsulinemic or normoglycemic males, and less prevalent in moderately diabetic males. Atrophic changes in islets of severely diabetic males were reflected by reduced islet numbers, approximately 10 to 20 per $\mathrm{cm}^{2}$. Extrainsular beta cells were observed in all pancreas samples (20 to 30 cell clusters per $\mathrm{cm}^{2}$ pancreas profile, but $<10$ per $\mathrm{cm}^{2}$ in chronically diabetic males). This suggests the potential for beta cell neogenesis even in severely diabetic males.

Although earlier studies suggested a possible defect in the development of pancreatic peptide-positive (PP) cells in the islets of NZO/Wehi mice (Gates and Lazarus, 1977; Gates et al, 1972, 1974), we observed numerous granulated PP-cells, as well as glucagoncontaining alpha cells. Although less numerous, somatostain containing delta cells were also demonstrable by immunochemical staining (Fig. 5, B to D). Non-beta cells do not form a mantle-like zone in islets in which the beta cell mass has undergone hypertro-

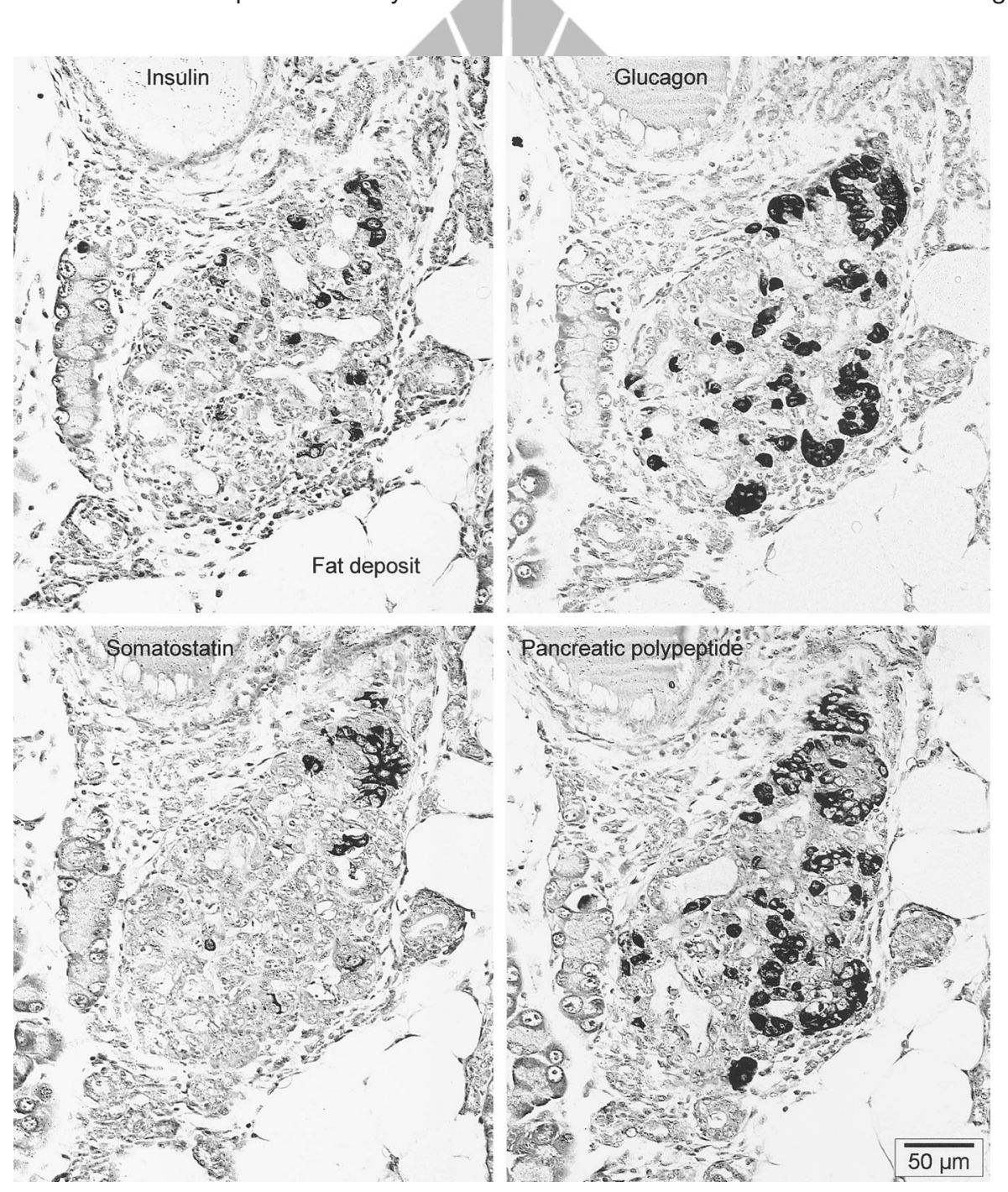

Figure 5.

Islet of a severely diabetic NZO/HI male at the age of 52 weeks (BG concentration: $680 \mathrm{mg} / \mathrm{dl}$, IRI concentration: $11.8 \mu \mathrm{U} / \mathrm{ml}$ ). Serial sections were immunostained for insulin, glucagon, somatostatin, and pancreatic polypeptide. Intra-islet ducts have formed. The remaining endocrine cells are predominately of the non-beta cell species. 
phy and hyperplasia, but are scattered throughout the islet. In hyperplastic islets of nondiabetic, hyperinsulinemic NZO/HI males, these non-beta endocrine cell types represent, on average, $10 \%$ of the islet volume. This corresponds to approximately $0.3 \%$ of the pancreatic volume. In islets of diabetic males, non-beta endocrine cell types represent $20 \%$ to $70 \%$ of the islet volume, depending on the severity of diabetes (Fig. 5, A to D). Compared with nondiabetic NZO/HI males, the fractional volume in the pancreas of these nonbeta endocrine cells is lower by approximately a factor of 2 , whereas the volume fraction of beta-cells is, on average, lower by a factor of 3 to 4 . This indicates a general loss of endocrine cells, but with the beta cell population primarily affected.

During the phase of islet mass expansion, focal perivascular/periductular leukocytic infiltrates were commonly observed in pancreata of both sexes. However, increases were noted in both the number and the size of these leukocytic infiltrates with increasing severity of diabetes in males. In chronically diabetic males aged 52 weeks, infiltrates were predominantly located along the main pancreatic ducts and formed follicle-like aggregates adjacent to islets. Because pancreatic islets were usually clustered around these expanding foci of leukocytes, peri-insulitis was frequently observed. As illustrated in Figure 2C, some of these perivascular infiltrates were more widely disseminated, producing focal pancreatitis. Figure 2C, although depicting a younger diabetic male, illustrates this combination of atrophic islets, peri-insulitis, and pancreatitis frequently seen in 52-week-old diabetic males.

\section{Lymphocyte Subsets in Leukocytic Infiltrates}

Immunocytochemical-staining for B- and T-lymphocyte cell surface antigens in the periductular/perivascular aggregations in the pancreas, regardless of association with islets, revealed a predominance of $\mathrm{CD}^{+}{ }^{+}$ B-lymphocytes (up to 70\%). Immunocytochemical staining of the peri-insular leukocytic population around an islet in a diabetic 52-week-old NZO/HI male is shown in Figure 6. Figure $6 \mathrm{~A}$ illustrates the focal nature of the islet-associated leukocytic aggregates, concentrating in the perivascular and periductular zones adjacent to the islets. Semiadjacent sections containing the same periinsular aggregate, but immunostained for $\mathrm{CD}^{+}$ T-lymphocytes (Fig. 6B), CD19 ${ }^{+}$B-lymphocytes (Fig. $6 \mathrm{C}$ ), or $\mathrm{CD}^{+}$cells (Fig. 6D), reflect a larger B- than T-lymphocyte composition. Further, the CD5 immunostaining pattern appears to overlap more with $\mathrm{CD}^{+}{ }^{+}$ staining B-lymphocytes than with $\mathrm{CD}^{+}$staining T cells, suggesting that some of these $\mathrm{CD}_{19}{ }^{+} \mathrm{B}$-lymphocytes may also be of the $\mathrm{CD}^{+} \mathrm{B} 1-\mathrm{B}$ subset. The $\mathrm{CD} 3^{+} \mathrm{T}$ cells tended to be outside the $\mathrm{CD}_{19^{+}}$staining B-lymphocytes in follicular aggregates and often extended into the exocrine parenchyma. To confirm this finding, a series of 22 peri-insular infiltrates selected from 5 diabetic males was analyzed. The total leukocyte number per infiltrate and the relative frequencies of lymphocyte subsets varied in individual infiltrates. However, in 13 of 15 extended infiltrates (total cell number $>100$ ), the relative frequencies of $\mathrm{CD}^{+}$cells significantly exceeded those of $\mathrm{CD} 3^{+}$ cells, with ratios of $\mathrm{CD}^{+} / \mathrm{CD} 3^{+}$cells varying between 1.2 and 2.5 .

Quantitative analysis of semiadjacent sections immunocytochemically stained for CD4 versus CD8 showed that $\mathrm{CD} 4^{+} \mathrm{T}$ cells were at least 3-fold more numerous than $\mathrm{CD}^{+} \mathrm{T}$ lymphocytes. In three serial sections stained for CD3, CD4, and CD8, respectively, the total of $\mathrm{CD}^{+}$plus $\mathrm{CD}^{+}$subset counts per infiltrate closely approximated the counts for $\mathrm{CD}^{+} \mathrm{T}$ lymphocytes in the same infiltrate. Average values per pancreas are summarized in Table 1.

Electron micrographic analysis of NZO islets with leukocytic involvement revealed small numbers of intra-islet lymphocytes and macrophages. Figure 7 shows an intra-islet lymphocyte in the islet of a 52month-old nondiabetic NZO female. Figure 8 shows an intra-islet macrophage in a diabetic male of the same age. This is in accordance with light microscopic observations. F4/80-stainable macrophages assessed by light microscopy were generally seen at the outside of islets. However, occasional intra-islet F4/80-labeled cells were detectable. One of the most interesting features of the electron micrographic survey of the peri-insular infiltrates was the detection of variable numbers of plasma cells (Fig. 9). Another noteworthy ultrastructural observation was the presence of budding C-type retrovirus particles emanating primarily from the exocrine parenchyma adjacent to islets. Figure 10 shows a macrophage-like cell phagocytosing these retroviral particles; this cell already contains phagocytosed beta cell debris.

\section{Discussion}

In this study, we report a variety of morphologic features of the pancreatic islet histopathology characterizing the $\mathrm{NZO} / \mathrm{HI}$ male diabetes model. Some of these features are shared with other polygenic mouse models for obesity, hyperinsulinemia, and T2D. $\mathrm{NZO} / \mathrm{HI}$ mice respond to an increased demand for insulin by enhanced beta cell proliferation entailing the expansion of beta cell mass and the formation of hyperplastic islets (Junger et al, 2001). Similar responses typify other rodent models, which are characterized by polygenic T2D-like syndromes. Comparable compensatory growth of beta cell mass is observed in inbred mouse strains, including the KK mouse (Ikeda, 1994) and the TSOD mouse (Suzuki et al, 1999), in hybrid mouse strains like $(\mathrm{C} 3 \mathrm{H} / \mathrm{HeJ} \times$ C57BL/6J)F1 (lona et al, 1986) or in BTBR $\times$ B6Lep ${ }^{o b} /$ Lep $^{o b}$ outcrosses (Stoehr et al, 2000), as well as in mice doubly heterozygous for targeted mutations in the insulin receptor and insulin receptor substrate-1 (IRS-1) encoding genes (Bruning et al, 1997; Kido et al, 2000). In NZO/HI males, hyperinsulinemia and the transition to overt diabetes is associated with progressive morphologic abnormalities; eg, beta cell degranulation and/or distortion of the islet architecture, features also reported for other mouse models. In BTBR $\times$ B6-Lep $p^{a b} /$ Lep $^{a b}$ outcrosses (Stoehr et al, 2000), the 


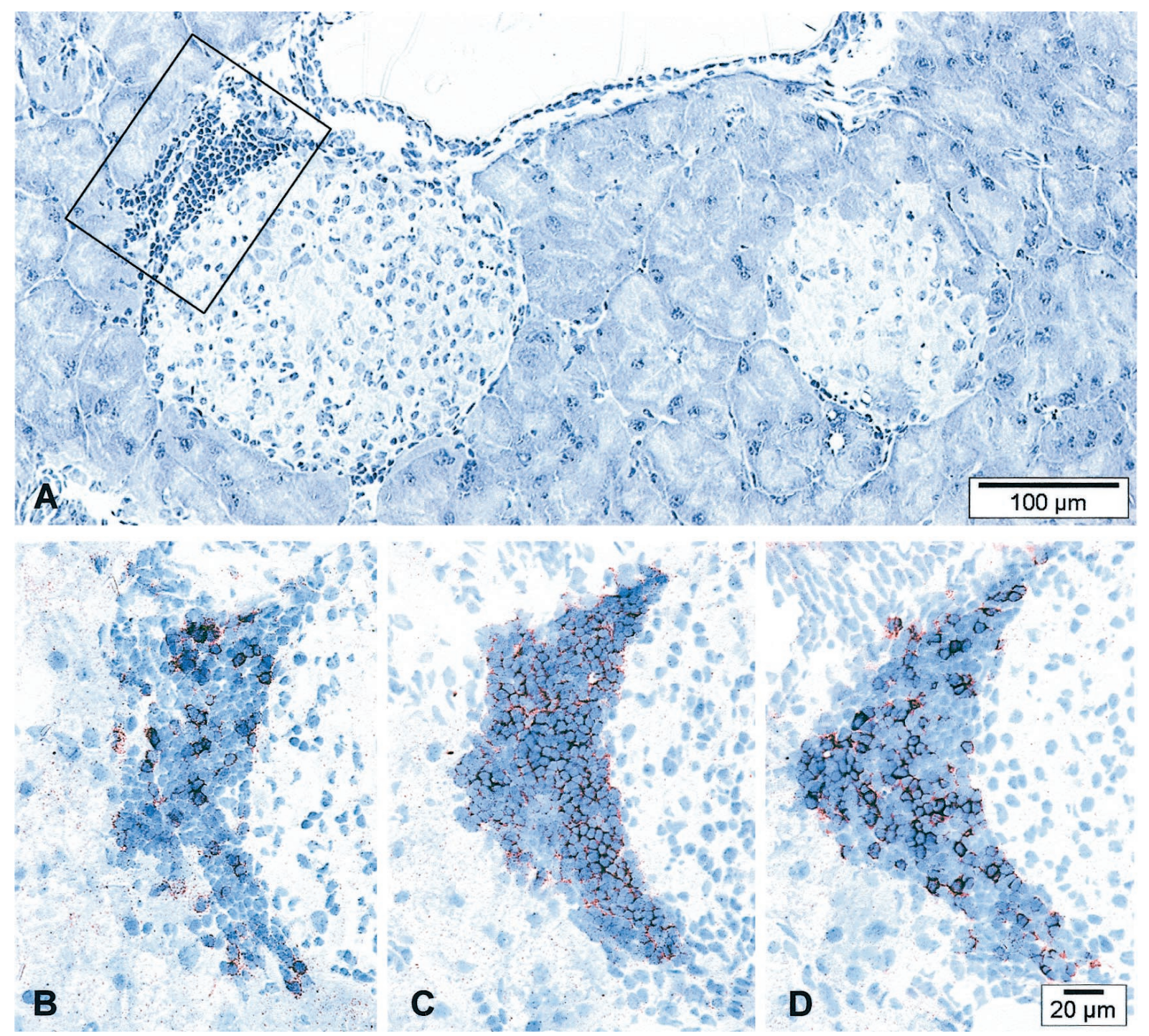

Figure 6.

Example of pancreatic lymphocytic infiltrates in a diabetic NZO/HI male at 52 weeks. A, Hematoxylin-stained cryosection showing a typical peri-insular leukocytic infiltrate. Note the exocrine cell inclusions in the second islet profile. B to D, Enlargements of the field denoted by the rectangle in (A). Consecutive sections were immunostained for CD3, CD19, and CD5.

\section{Table 1. Percentages of Lymphocyte Subsets in Infiltrates of NZO/HI Male Mice}

\begin{tabular}{ccccccccccc}
\hline $\begin{array}{c}\text { Mouse } \\
\text { no. }\end{array}$ & $\% \mathrm{CD} 9^{+}$ & $n$ & $\% \mathrm{CD}^{+}$ & $n$ & $\% \mathrm{CD}^{+}$ & $n$ & $\% \mathrm{CD}^{+}$ & $n$ & $\% \mathrm{CD}^{+}$ & $n$ \\
\hline 1 & $25.8 \pm 11.3$ & $(5)$ & $34.9 \pm 18.1$ & $(6)$ & $23.9 \pm 9.0$ & $(6)$ & $34.5 \pm 30.7$ & $(2)$ & $5.0 \pm 6.0$ & $(2)$ \\
2 & $54.7 \pm 16.2$ & $(3)$ & $48.1 \pm 20.3$ & $(4)$ & $39.4 \pm 18.7$ & $(4)$ & 40.6 & $(1)$ & 15.8 & $(1)$ \\
3 & 55.1 & $(1)$ & $30.2 \pm 8.7$ & $(3)$ & $21.2 \pm 8.8$ & $(3)$ & $20.1 \pm 2.6$ & $(3)$ & $5.5 \pm 3.1$ & $(3)$ \\
4 & $50.9 \pm 16.0$ & $(4)$ & $32.6 \pm 12.5$ & $(4)$ & $23.9 \pm 5.3$ & $(4)$ & nd & & nd & \\
5 & $20.8 \pm 9.5$ & $(3)$ & $37.4 \pm 12.5$ & $(5)$ & $15.4 \pm 6.6$ & $(5)$ & $17.6 \pm 7.7$ & $(4)$ & $3.9 \pm 2.1$ & $(4)$ \\
\hline
\end{tabular}

nd, not determined.

Data are means \pm SD.

Numbers in parentheses are the number of infiltrates analyzed per mouse.

inclusions of exocrine cells into degenerating islets ("exocrinization") were observed that were comparable to those in NZO/HI mice. However, in contrast to the former model, in both NZO females and males, lymphocytic infiltrates occur that increase in number and size with increasing severity of diabetes in males. This expansion of infiltrates was found to be paralleled by a decrease in $\mathrm{V}_{\mathrm{v}}$ isl.

The companion article (Haskell et al, 2002) extended previous studies showing strain similarities between 


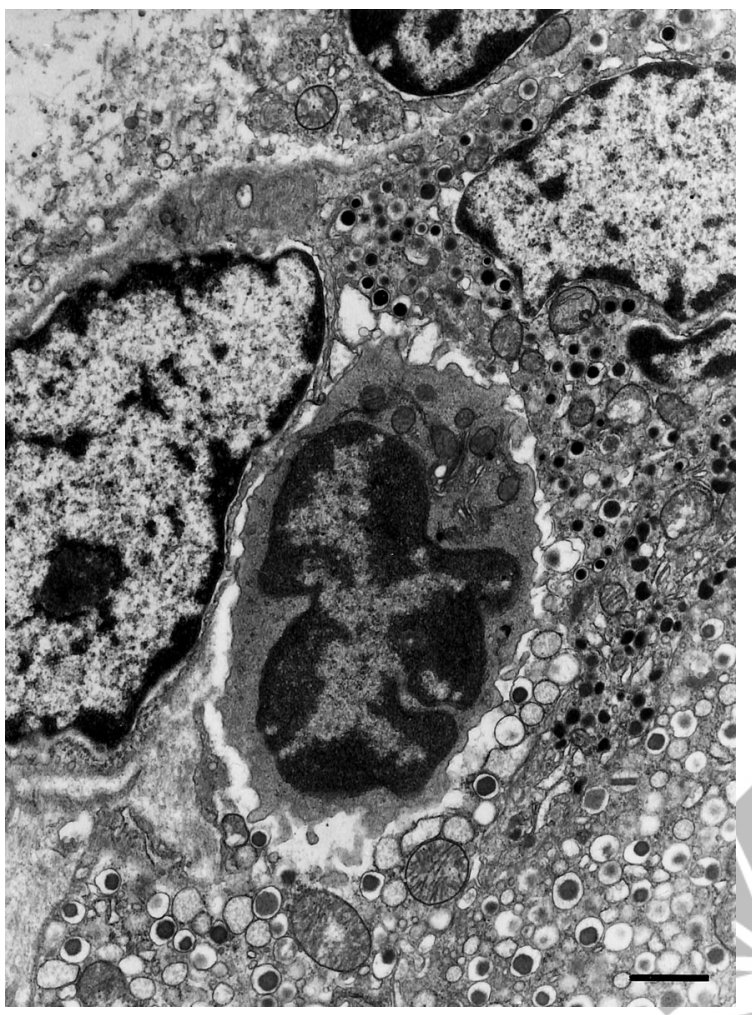

Figure 7.

Detail of an islet from a 52-week-old female. A lymphocyte contacts both a granulated beta and an alpha cell. (Bar $=1 \mu \mathrm{m}$.)

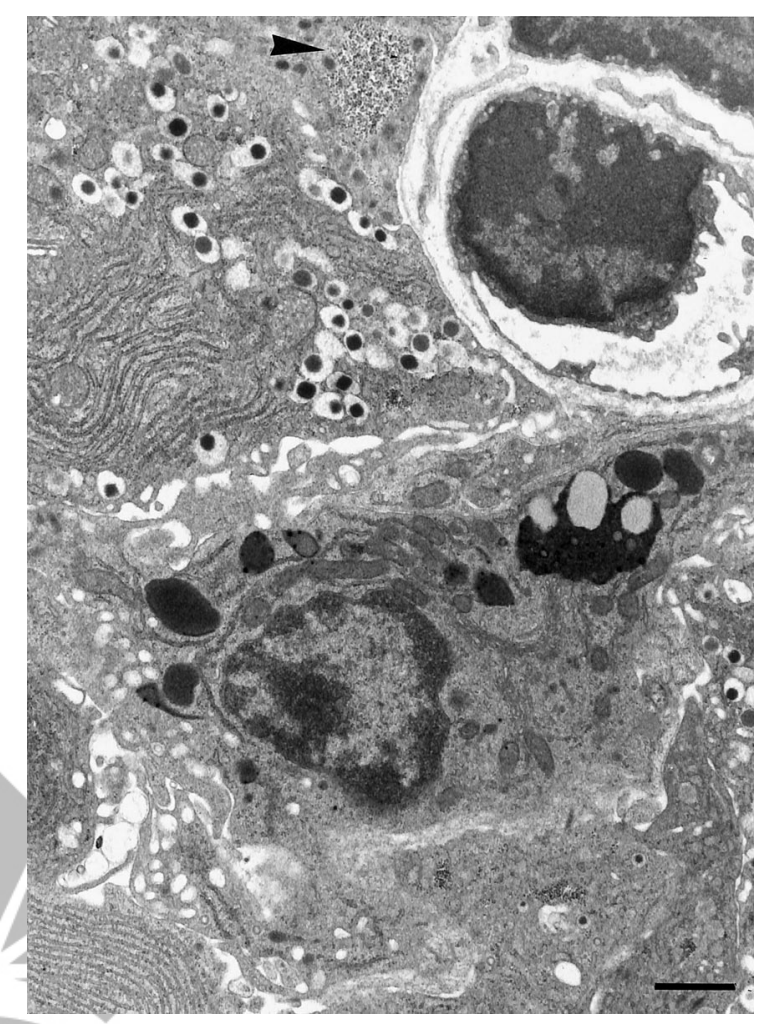

Figure 8.

Macrophage in contact with beta cells of a 52-week-old male. Glycogen deposits (arrowhead) are occasionally seen. (Bar $=1 \mu \mathrm{m}$.)
NZO mice and the nondiabetic autoimmune-prone NZB and NZW strains. Several histopathologic features are associated with diabetes pathogenesis in the NZO male that deserve comment. The first is the unusual association of / high percentages of B-lymphocytes, particularly B-lymphocytes with phenotypes suggestive of the B1-B natural autoantibodyproducing subset, in the peri-insular aggregates. Data reported in the companion article show that high frequencies of B1-B cells in the spleen is an NZO strain characteristic in common with NZB and NZW mice (Haskell et al, 2002). The presence of plasma cells immediately adjacent to the islet cells seems unique to this diabetes model; it is not a feature of the NOD model of autoimmune, T-cell-mediated type I diabetes. It should be noted that female mice are generally more prone to autoimmune pathology than are males. NZO females develop leukocytic aggregates in pancreas, often producing a peri-insulitis, but NZO females are resistant to diabetes. What distinguishes the two sexes is the male sex-limited increase in the number and the size of these leukocytic infiltrates, with both parameters increasing with increasing severity of diabetes $\left(R^{2}=0.70\right.$ for numbers of infiltrated islets in male pancreas correlated with increasing blood glucose concentration). Hence, it is logical to conclude that the expansion of leukocytes associated with the degenerate islets in NZO males do not represent primary effectors of beta cell destruction in this model, but rather represent a secondary response to beta cell death as evidenced by the pres- ence of phagocytotic macrophages within the islets. Insulitis reactive to, rather than the cause of initial beta cell destruction in mice, is also observed in male mice of strains süsceptible to insulin dependent diabetes elicited by multiple low doses of the beta cell toxin, streptozotocin (Leiter et al, 1999). Certain immunologic manifestations previously associated with beta cell destruction in mice homozygous for the diabetes mutation at the leptin receptor locus $\left(L e p r^{d b}\right)$ have been shown to be secondary to pathogenesis by introduction of a variety of immunodeficiency genes (Leiter et al, 1987).

- Accelerated beta cell destruction has previously been observed in a Lepr ${ }^{d b}$-congenic mouse stock wherein C-type retroviruses were shed from the beta cells (Leiter, 1985). The NZB strain is well-known for development of autoantibodies to an endogenous C-type retrovirus (NZB-tropic) (Izui et al, 1979). We have confirmed by Southern blot analysis (using an NZB-tropic envelop-specific gene probe) the presence of at least one NZB-tropic proviral gene common to both NZB and NZO genomes. Although we have observed the presence of large numbers of shed particles in the pancreatic interstitia, and their engulfment by macrophages, we have not observed retroviral shedding from beta cell surfaces, nor have we observed them intracellularly. Thus, phagocytosed viral particles observed in macrophages present in the pancreatic interstitium suggest that retroviral antigens were being processed and thus possibly priming an antiretroviral immune response. However, the ab- 

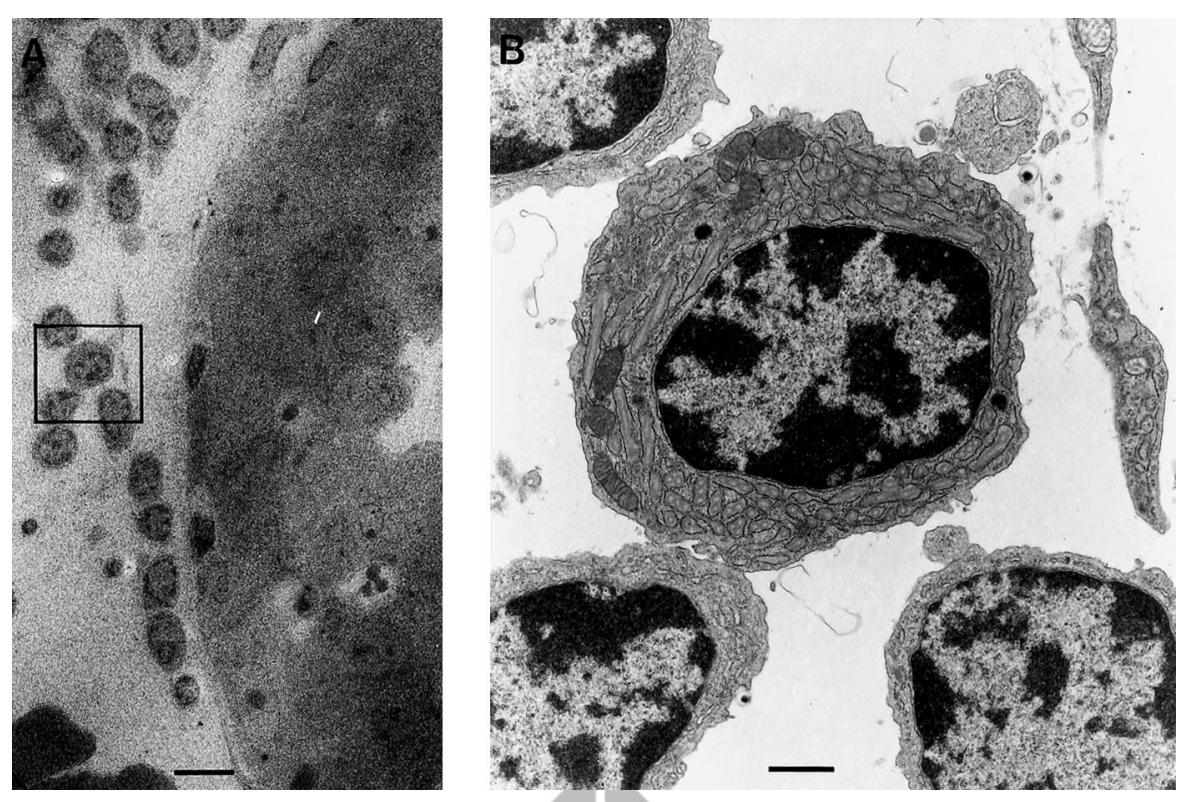

Figure 9.

A, Survey of an islet with peri-insular leukocytes. (Bar $=10 \mu \mathrm{m}$.) B, Enlargement of area denoted by the rectangle to show presence of plasma cells. (Bar $=1 \mu \mathrm{m}$.)

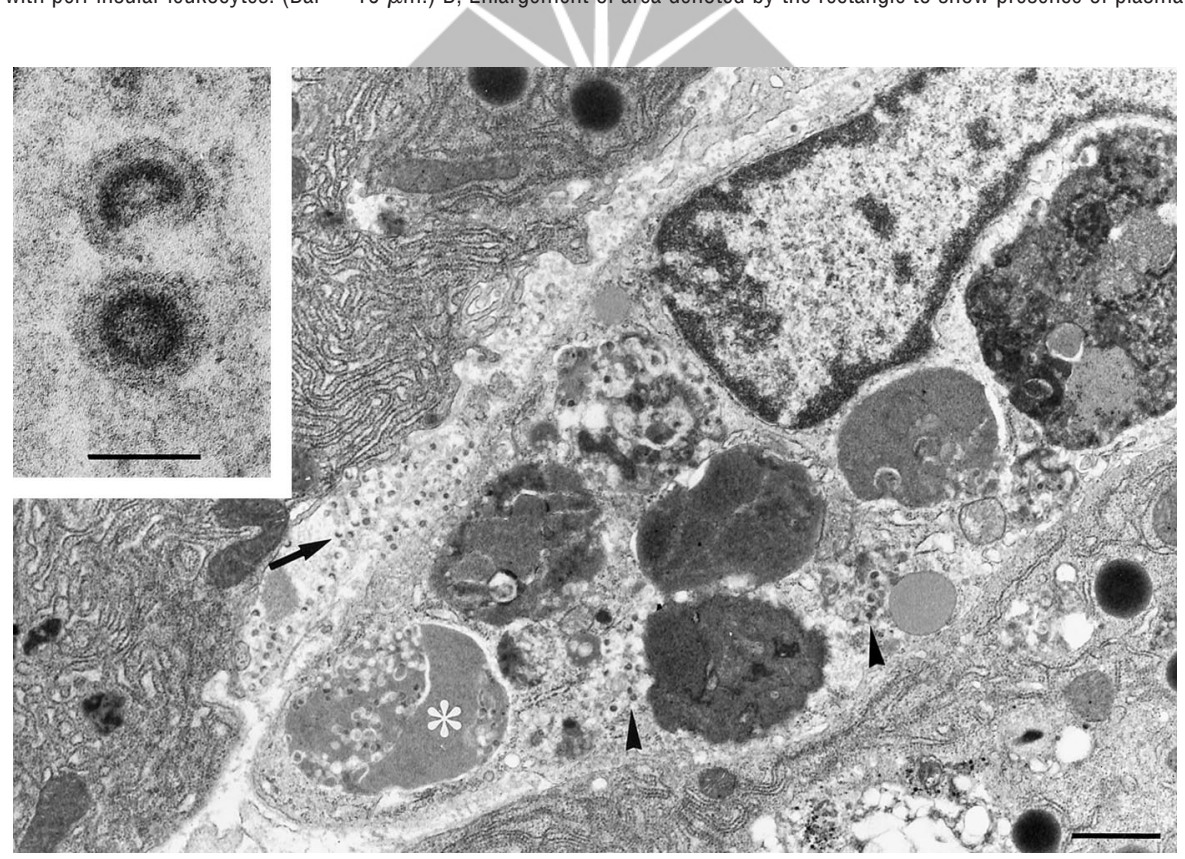

\section{Figure 10.}

Pancreas section of a 52-week-old male. Intersitial macrophage between pancreatic acinar cells, with phagocytosed virus particles (arrowheads) and beta cell debris (white asterisk). The interstitium contains many virus particles (arrow) shed from acinar cells. (Bar $=1 \mu \mathrm{m}$.) Inset shows typical type $\mathrm{C}$ particle morphology at high magnification. (Bar $=0.1 \mu \mathrm{m}$.)

sence of morphologic evidence that retroviral particles were being shed at the beta cell surface does not suggest that the beta cells would be targeted by virus-reactive lymphocytes or antiviral antibodies.

In contrast to the insulin-resistant form of diabetes developing in Lepr ${ }^{d b}$ mice, which still developed in stocks made congenic for immunodeficiency mutations that compromised T- or B-lymphocyte functions (Leiter et al, 1987), the companion article shows that NZO males homozygous for a disrupted immunoglobulin heavy chain gene, and thus B-lymphocyte defi- cient, were more diabetes resistant than B-lymphocyte intact males (Haskell et al, 2002). The low-titer IgM autoantibodies to the insulin receptor known to be present in NZO/Wehi mice have been suggested as contributory to the insulin resistance that becomes progressively more severe (Harrison and Itin, 1979). We have identified early development of hyperinsulinemia, presumably a reflection of insulin resistance, as an accurate predictor of which males would transit from impaired glucose tolerance into overt type 2 diabetes (Reifsnyder et al, 2000). Hence, 
the level of humoral autoimmunity against insulin receptors, coupled with male sex-specific factors, could determine which $\mathrm{NZO} / \mathrm{HI}$ males develop clinical diabetes and which do not. In a human patient with type B syndrome of severe insulin resistance, antiinsulin receptor autoantibodies were shown to produce insulin resistance by desensitizing signaling through the receptor via a stable association with the IRS-1 and IRS-2 docking molecules (Auclair et al, 1999). Although the peri-insular aggregates contained both $\mathrm{CD}^{+}$and $\mathrm{CD}^{+}{ }^{+} \mathrm{T}$ cells (with the ratio heavily in favor of $\mathrm{CD}^{+}$cells), we have no evidence to suggest a primary role for $\mathrm{T}$ cell autoimmunity in diabetes etiopathogenesis in these males. Genetic segregation analysis conducted to locate NZO-contributed diabetogenic loci failed to identify its $\mathrm{H}_{2}^{\mathrm{z}}$ haplotype, associated with lupus and glomerulonephritis in (NZB $\times$ NZW) F1 mice (Hirose et al, 1983), as a diabetogenic contributor, as might be anticipated if $\mathrm{T}$ cell autoimmunity were a primary event. The fact that NZO mice express the $\mathrm{H}_{2}{ }^{\mathrm{z}}$ haplotype casts doubt on earlier reports that transplantation of $\mathrm{C} 57 \mathrm{BL} / 6 \mathrm{~J}\left(\mathrm{H} 2^{\mathrm{b}}\right)$ islets into diabetic NZO recipients "cured" the diabetes (Gates et al, 1972, 1974). An alloimmune rejection would be anticipated across this major histocompatibility barrier. Further, the observation that NZO islets are rich in PP cells refutes an earlier suggestion that there is a genetic lack of PP, and further makes it unlikely that PP from other islet sources would be curative, as reported previously (Gates and Lazarus, 1977).

In summary, the present study characterizes the male sex-limited histopathologic changes in the pancreata of NZO mice at both the light and electron microscopic levels. The endocrinologic basis for male sex-limited susceptibility to T2D in most rodent models studied to date remains to be elucidated. A unique feature of this diabetes model is the accumulation of B-lymphocyte enriched peri-insular leukocytic aggregates in both diabetes-resistant females and diabetes-prone males. Equally unusual was the presence of variable numbers of plasma cells in periinsular aggregates observed in chronically diabetic males. Presumably, plasma cells in combination with increased numbers of B1-B lymphocytes may contribute to the production of the low-affinity lgM insulin receptor autoantibodies circulating in NZO mice. We have confirmed a previous report (Harrison and Itin, 1979) of low affinity lgM insulin receptor autoantibodies in NZO/HILt mice of both sexes, but with highest titers in older diabetic males. These have been conjectured to contribute to the progressively more severe insulin resistance. Autoantibodies to insulin, known to develop in autoimmune diabetes-prone NOD/Lt mice (Yu et al, 2000), have not been detected in a small number of NZO serum samples screened (Mark Atkinson, University of Florida, personal communication). The ultrastructural appearance of beta cells in chronically diabetic males, including betadegranulation and dilatation of the rough endoplasmic reticulum, were consistent with hypersecretory stress. This, in turn, probably reflected a progressively more severe insulin resistance. The observation that B-lymphocyte deficiency can retard development of hyperglycemia suggests that B lymphocytes, either systemically or regionally within the pancreas, may be contributing to the development of a diabetogenic level of insulin resistance in males.

\section{Materials and Methods}

\section{Mice}

$\mathrm{NZO/HI} \mathrm{(Düsseldorf} \mathrm{colony)} \mathrm{mice} \mathrm{were} \mathrm{maintained} \mathrm{in} \mathrm{a}$ specific pathogen-free (SPF, barrier) facility. They were given access ad libitum to autoclaved drinking water and a diet containing $4.5 \%$ fat, $51.5 \%$ carbohydrate, and $21 \%$ protein (SSNIFF, Soest, Germany). Mice were weaned at 3 weeks of age. Same-sex litter mates were caged in groups of three to five. NZO/HILt mice (Bar Harbor colony derived from NZO/HI) were maintained at high SPF but not barrier level and fed a comparable diet (NIH31, 4\% fat).

\section{Analytical Procedures}

Body weight recording and blood harvesting from the tip of the tail were performed between 8:00 am and 9:00 am on nonfasted mice. Nonfasting BG was determined by an automated glucose oxidase method (Care Diagnostica, Voerde, Germany) on $20 \mu \mathrm{l}$ of blood. Nonfasting serum IRI was assayed with a radioimmunoassay kit (Pharmacia Insulin Ria 100; Pharmacia AB, Uppsala, Sweden)

\section{Tissue Sampling and Processing for Pancreas Histology}

\section{NZO mice were necropsied between 24 and 52 weeks} of age. The total pancreas was excised and fixed either in Bouin's fluid or in 4\% paraformaldehyde in PBSline. Specimens were embedded in paraffin and sections were cut parallel to the long axis of the gland. From each pancreas, a series of 10 consecutive 5- $\mu \mathrm{m}$ sections was cut at sampling intervals of $0.3 \mathrm{~mm}$ of linear scan through the tissue. Sections were mounted on slides, and stained either with aldehyde fuchsin, or were immunocytochemically stained for insulin, glucagon, somatostatin, and pancreatic polypeptide using commercially available primary antibodies (DAKO Diagnostika, Hamburg, Germany) according to suppliers' directions.

\section{Morphometric Measurements}

The fractional volume of islets (eg, islet volume contained in the unit volume of pancreas, $V_{v}$ isl,) was estimated by light microscopic point counting (Weibel and Bolender, 1973). At least three sections per linear scan series were evaluated. At least one of the sections scanned per series contained a main duct. Large lumina of vessels and ducts as well as fat inclusions and lymph nodes were excluded from the test area. The numerical density of islet profiles per section area was determined and the individual islet profiles sorted into three classes according to their largest diameter. 
The size classes were $<250 \mu \mathrm{m},<450 \mu \mathrm{m}$, and $>450$ $\mu \mathrm{m}$, respectively. Small extrainsular clusters of beta cells detected either by aldehyde fuchsin staining or by immunocytochemically staining for insulin were counted separately.

\section{Islet Scores}

The morphologic integrity of islet profiles was judged according to the following criteria: (a) intact, (b) with signs of exocrinization, (c) peri-insular infiltration, (d) intrainsular infiltrations, and (e) presence of intrainsular ductules, with or without exocrinization, respectively.

\section{Tissue Sampling and Processing for the Characterization of Lymphocyte Subsets}

Pieces of the pancreas head, including parts of the duodenum, and pieces of the pancreas tail, including parts of the spleen, were frozen in melting 2-methylbutane and stored at $-60^{\circ}$ to $-80^{\circ} \mathrm{C}$. For sectioning, the frozen tissue blocks were attached to the cryostat chuck with a small amount of frozen tissue matrix OCTR. Serial sections were cut at $5 \mu \mathrm{m}$ and mounted on Histo Bond slides. The cryosections were air dried overnight, fixed in acetone, and stored at $-20^{\circ} \mathrm{C}$ until staining. Consecutive sections were stained at room temperature for CD19, CD5, CD3, CD4, CD8, and F4/80 using commercially available primary monoclonal antibodies (PharMingen, San Diego, California) according to the following protocol. Cryosections were rehydrated in PBS buffer for 5 minutes and postfixed in $1 \%$ paraformaldehyde in PBS buffer for 10 minutes. This step was found to improve the preservation of the tissue and was found to be essential for the quantification of lymphocyte subsets. After rinsing in buffer, the sections were incubated with the primary antibodies for 30 to 60 minutes in Tris- $\mathrm{NaCl}$ buffer containing $5 \%$ bovine serum albumin (BSA) at $\mathrm{pH}$ 7.6. Using the same buffer system, the sections were then incubated with biotinylated secondary antibodies and finally with streptavidin-coupled alkaline phosphatase, for 30 minutes, respectively. Alkaline phosphatase was detected using Fast Red Substrate (DAKO Diagnostika) containing $4 \mathrm{mmol} / \mathrm{l}$ Levamisol. After each incubation, the slides were rinsed in Tris- $\mathrm{NaCl}$ buffer, $\mathrm{pH} 7.6$, without BSA. Sections were counterstained in hematoxylin (Mayer).

\section{Lymphocyte Counts and Statistics}

Individual infiltrates were indexed on serial sections. Total cell numbers and positively labeled cells were counted using a computer-aided design. Neighboring sections were used for the comparison of the $\mathrm{CD} 5^{+}$ and $\mathrm{CD}^{+}$and the $\mathrm{CD}^{+}$and $\mathrm{CD}^{+}$relationship, respectively. From larger infiltrates 2 to 4 section planes per subsets were evaluated and progressively counted. The significance of the difference between the fraction of $\mathrm{CD}^{+}$and $\mathrm{CD}^{+}$cells and the fraction of $\mathrm{CD}^{+}$and $\mathrm{CD}^{+}$cells, respectively, was tested using $2 \times 2$ contingency tables and $\chi^{2}$ test; 95\% confidence limits were calculated according to Kleinbaum et al (1982).

\section{Tissue Sampling and Processing for Electron Microscopy}

Approximately $1 \mathrm{~mm}^{3}$ tissue blocks were fixed for 2 hours at room temperature by immersion in a solution of $1 \%$ paraformaldehyde and $2.5 \%$ glutaraldehyde in $0.19 \mathrm{~m}$ cacodylate buffer at $\mathrm{pH} 7.4$, postfixed in $2 \%$ OSO4 in $0.19 \mathrm{~m}$ cacodylate buffer, pH 7.4, for 2 hours, and subsequently block stained in $2 \%$ uranyl acetate in maleate buffer, $\mathrm{pH}$ 4.6. The specimens were dehydrated in graded ethanols and embedded in epoxy resin (Spurr, 1969). Toluidine-blue stained semithin sections were used to search for islets. Ultrathin sections were picked up onto Formvar-carboncoated grids, stained with lead citrate, and viewed in a transmission electron microscope (TEM 910; LEO Elektronenmikroskopie, Oberkochen, Germany).

\section{Acknowledgements}

We thank Dr. B. Haastert for assistance in the statistical analysis of morphometric data and Drs. David Serreze and Leonard Shultz for their critical review of this manuscript.

\section{References}

Auclair M, Vigouroux C, Desbois-Mouthon C, Deibener J, Kaminski P, Lascols O, Cherqui G, Capeau J, and Caron M (1999). Antiinsulin receptor autoantibodies induce insulin receptors to constitutively associate with insulin receptor substrate- 1 and -2 and cause severe cell resistance to both insulin and insulin-like growth factor I. J Clin Endocrinol Metab 84:3197-3206.

Bruning JC, Winnay J, Bonner-Weir S, Taylor SI, Accili D, and Kahn CR (1997). Development of a novel polygenic model of NIDDM in mice heterozygous for IR and IRS-1 null alleles. Cell 88:561-572.

Gates R, Hunt M, and Lazarus N (1974). Further studies on the amelioration of the characteristics of New Zealand obese (NZO) mice following implantation of islets of Langerhans. Diabetologia 10:401-406.

Gates RJ and Lazarus NR (1977). The ability of pancreatic polypeptides (APP and BPP) to return to normal the hyperglycaemia, hyperinsulinaemia and weight gain of New Zealand obese mice. Horm Res 8:189-202.

Gates RJ, Smith R, Hunt MI, and Lazarus NR (1972). Return to normal of blood-glucose, plasma-insulin, and weight gain in New Zealand obese mice after implantation of islets of Langerhans. Lancet 7777:567-570.

Harrison LC and Itin A (1979). A possible mechanism for insulin resistance and hyperglycaemia in NZO mice. Nature 279:334-336.

Haskell BD, Flurkey K, Duffy TM, Sargent EE, and Leiter EH (2002). The diabetes-prone NZO/HI strain. I. Immunophenotypic comparison to the related NZB/BinJ and NZW/LacJ strains. Lab Invest 82:833-842.

Hirose S, Nagasawa R, Sekikawa I, Hamaoki M, Ishida Y, Sato $H$, and Shirai $T$ (1983). Enhancing effect of $H$-2-linked NZW gene(s) on the autoimmune traits of (NZB X NZW)F1 mice. J Exp Med 158:228-233. 
Ikeda H (1994). KK mouse. Diabetes Res Clin Pract 24(Suppl):313-316.

Iona J, Gordon J, Yates A, and Fox H (1986). Obesity, hyperinsulinemia, and hyperplasia of the pancreatic islets in ageing $(\mathrm{C} 3 \mathrm{H} / \mathrm{HeJ} \times \mathrm{C} 57 \mathrm{BL} / 6 \mathrm{~J}) \mathrm{F} 1$ hybrid mice. Horm Metabol Res 18:210-212.

Izui S, McConahey PJ, Theofilopoulos AN, and Dixon FJ (1979). Association of circulating retroviral gp70-anti-gp70 immune complexes with murine systemic lupus erythematosus. J Exp Med 149:1099-1116.

Junger E, Jeruschke K, Lange C, and Leiter EH (2001). Beta-cell proliferation and beta-cell degeneration in the New Zealand obese (NZO) mouse (Abstract). Diabetes und Stoffwechsel 10:13.

Kido Y, Burks DJ, Withers D, Bruning JC, Kahn CR, White MF, and Accili D (2000). Tissue-specific insulin resistance in mice with mutations in the insulin receptor, IRS-1, and IRS-2. J Clin Invest 105:199-205.

Kleinbaum DG, Kupper LL, and Morgenstern H (1982). Epidemiologic research: Principles and quantitative methods. Belmont: Wadsworth Publishing, 299.

Leiter EH (1985). Type C retrovirus production by pancreatic beta cells. Association with accelerated pathogenesis in $\mathrm{C} 3 \mathrm{H}-d b / d b$ ("Diabetes") mice. Am J Pathol 119:22-32.

Leiter EH, Gerling IC, and Flynn JC (1999). Spontaneous insulin dependent diabetes mellitus (IDDM) in nonobese diabetic (NOD) mice: Comparisons with experimentallyinduced IDDM. In: McNeill JH, editor. Experimental models of diabetes. Boca Raton: CRC Press, 257-295.

Leiter EH and Herberg L (1997). The polygenetics of diabesity in mice. Diabetes Reviews 5:131-148.

Leiter EH, Prochazka M, and Shultz LD (1987). Effect of immunodeficiency on diabetogenesis in genetically diabetic (db/db) mice. J Immunol 138:3224-3229.

Leiter EH, Reifsnyder PC, Flurkey K, Partke H-J, Junger E, and Herberg $L$ (1998). Non-insulin dependent diabetes genes in mice: Deleterious synergism by both parental genomes contributes to diabetogenic thresholds. Diabetes 47:12871295.

Martin F and Kearney JF (2001). B1 cells: Similarities and differences with other B cell subsets. Curr Opin Immunol 13:195-201.
Melez KA, Attallah AM, Harrison ET, and Raveche ES (1985). Immune abnormalities in the diabetic New Zealand obese (NZO) mouse: Insulin treatment partially suppresses splenic hyperactivity measured by flow cytometric analysis. Clin Immunol Immunopathol 36:110-119.

Melez KA, Harrison LC, Gilliam JN, and Steinberg AD (1980). Diabetes is associated with autoimmunity in the New Zealand obese (NZO) mouse. Diabetes 29:835-840.

Reifsnyder PC, Churchill G, and Leiter EH (2000). Maternal environment and genotype interact to establish diabesity in mice. Genome Res 10:1568-1578.

Seemayer TA and Colle E (1984). Pancreatic cellular infiltrates in autoimmune-prone New Zealand black mice. Diabetologia 26:310-313.

Spurr AR (1969). A low-viscosity epoxy resin embedding medium for electron microscopy. J Ultrastruct Res 26:31-43.

Stoehr JP, Nadler ST, Schueler KL, Rabaglia ME, Yandell BS, Metz SA, and Attie AD (2000). Genetic obesity unmasks nonlinear interactions between murine type 2 diabetes susceptibility loci. Diabetes 49:1946-1954.

Suzuki W, lizuka S, Tabuchi M, Funo S, Yanagisawa T, Kimura M, Sato T, Endo T, and Kawamura H (1999). A new mouse model of spontaneous diabetes derived from ddY strain. Exp Anim 48:181-189.

Taguchi N, Hashimoto Y, Hsu T, Ansari AA, Shultz L, Dorshkind K, Ikehara S, Naiki M, and Gershwin ME (2001). B cells are selectively associated with thymic cortical but not medullary pathology in NZB mice. J Autoimmun 16:393-400.

Taylor BA, Wnek C, Schroeder D, and Phillips SJ (2001). Multiple obesity QTLs identified in an intercross between the $\mathrm{NZO}$ (New Zealand obese) and the SM (small) mouse strains. Mamm Genome 12:95-103.

Weibel ER and Bolender RP (1973). Stereological techniques for electron microscopic morphometry. In: Hayat MA, editor. Principles and techniques of electron microscopy. New York: Van Norstrand Reinhold, 239-296.

Yu LP, Robles DT, Abiru N, Kaur P, Rewers M, Kelemen K, and Eisenbarth GS (2000). Early expression of antiinsulin autoantibodies of humans and the NOD mouse: Evidence for early determination of subsequent diabetes. Proc Natl Acad Sci USA 97:1701-1706.

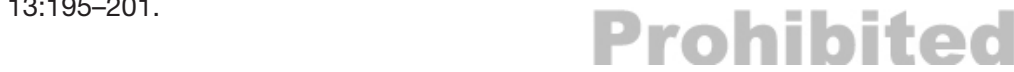

